\title{
m-Health Policy Readiness and Enabling Factors: Comparisons of Sub-Saharan Africa and Organization for Economic Cooperation and Development Countries
}

Seohyun Lee, PhD, ${ }^{1,2}$ Charles E. Begley, PhD, ${ }^{1}$

Robert Morgan, PhD, ${ }^{1}$ Wenyaw Chan, PhD, ${ }^{3}$

and Sun-Young Kim, PhD $D^{2,4}$

${ }^{1}$ Department of Management, Policy and Community Health, School of Public Health, University of Texas Health Science Center at Houston, Houston, Texas.

${ }^{2}$ Institute of Health and Environment, Center for Global Health Research, Graduate School of Public Health, Seoul National University, Seoul, South Korea.

${ }^{3}$ Department of Biostatistics and Data Science, School of Public Health, University of Texas Health Science Center at Houston, Houston, Texas.

${ }^{4}$ Department of Public Health Science, Graduate School of Public Health, Seoul National University, Seoul, South Korea.

\section{Abstract}

Background: As an innovative solution to poor access to care in low- and middle-income countries (LMICs), m-health has gained wide attention in the past decade.

Introduction: Despite enthusiasm from the global health community, LMICs have not demonstrated high uptake of mhealth promoting policies or public investment.

Materials and Methods: To benchmark the current status, this study compared m-health policy readiness scores between subSaharan Africa and high-income Organization for Economic Cooperation and Development (OECD) countries using an independent two-sample t test. In addition, the enabling factors associated with m-health policy readiness were investigated using an ordinal logistic regression model. The study was based on the m-health policy readiness scores of 112 countries obtained from the World Health Organization Third Global Survey on e-Health.

Results: The mean m-health policy readiness score for subSaharan Africa was statistically significantly lower than that for OECD countries $(\mathrm{p}=0.02)$. The enabling factors significantly associated with $m$-health policy readiness included information and communication technology development index (odds ratio [OR] 1.57; 95\% confidence interval [CI] 1.12-2.2), e-health education for health professionals (OR 4.43; 95\% CI 1.60-12.27), and the location in sub-Saharan Africa (OR 3.47; 95\% CI 1.06-11.34).

Discussion: The findings of our study suggest dual policy goals for m-health in sub-Saharan Africa. First, enhance technological and educational support for m-health. Second, pursue global collaboration for building m-health capacity led by sub-Saharan African countries with hands-on experience and knowledge. Conclusion: Globally, countries should take a systematic and collaborative approach in pursuing m-health policy with the focus on technological and educational support.

Keywords: $m$-health, policy, sub-Saharan Africa, WHO Global Survey on e-health, telemedicine

\section{Introduction}

U sing mobile devices to improve upon three overarching quality measures of public health-(1) structure, (2) process, and (3) outcome-has become increasingly popular in low- and middle-income countries (LMICs) as well as in developed countries. ${ }^{1,2}$ M-health is an important component of e-health, particularly in LMICs, because it improves access to care and lowers the cost of health service delivery. ${ }^{3}$ In the global health context, m-health has been implemented to serve multiple purposes as follows: (1) communication tool for behavior change, (2) clinic appointment or medication reminders, (3) monitoring and management of diseases and pandemic, (4) data collection and tracking, (5) enhanced communication among health professionals or between patients and providers, and (6) education for health professionals or patients. ${ }^{4}$

Given its potential value and enthusiasm among key actors of global health, m-health investment is an attractive policy option for governments, health program implementers, policy

(C) Seohyun Lee et al. 2018; Published by Mary Ann Liebert, Inc. This article is available under the Creative Commons License CC-BY-NC (http://creativecommons.org/licenses/by-nc/4.0). This license permits non-commercial use, distribution and reproduction in any medium, provided the original work is properly cited. Permission only needs to be obtained for commercial use and can be done via RightsLink. 


\section{M-HEALTH POLICY READINESS}

makers, philanthropists, nongovernmental organizations, industry and international organizations to solve public health challenges that LMICs face.

However, there remain two broad issues regarding m-health policy development and implementation. First, policy support by LMICs of $m$-health programs has been limited by healthcare infrastructure and resources. ${ }^{5,6}$ Several studies have recognized the need for robust policy support for m-health in LMICs, but no study has attempted to quantify the existing disparities in m-health policy readiness between LMICs and developed countries. $^{5,7-10}$ Second, there is little empirical evidence on what factors can contribute to increased policy uptake and how these factors can be effectively applied to the policy agenda. Even though m-health has been recognized as a useful e-health tool for strengthening health systems in limited resource settings, the mechanisms of m-health adoption as part of national e-health policy are still not well understood. ${ }^{5,11}$

To address this gap in the literature, this study had two objectives. First, a measure of the level of m-health policy readiness was compared between sub-Saharan Africa and high-income countries from Organization for Economic Cooperation and Development (OECD), using the data from the Third Global Survey on e-Health by the World Health Organization (WHO). Sub-Saharan Africa was chosen as focus of the study because there has been an explosion in m-health investment in this region to address public health problems in terms of financial resources, workforce, and infrastructure. ${ }^{12,13}$ To benchmark the status of m-health policy uptake in the region, OECD countries are compared to sub-Saharan Africa as they are known to be relatively wealthy with larger amount of resources and policy support.

The second objective was to identify enabling factors associated with $m$-health policy readiness by examining the cases of 112 countries that provided sufficient data from the same survey on e-health by WHO. Given varying degrees of technological bases and resources available in different countries, it is important to understand key enabling factors for scalable and sustainable m-health development. The evidence from this research can be used to inform policy makers responsible for policy planning for m-health development at the national or international level.

\section{Materials and Methods}

\section{DATA SOURCES}

Data on m-health policy readiness were obtained from the Third Global Survey on e-Health conducted by the WHO Global Observatory for e-Health in $2015 .{ }^{14}$ As e-health is an umbrella term for the use of information and communication technology (ICT) in healthcare, the survey provides the global landscape of e-health activities, including e-health foundations, m-health, telehealth, e-learning, electronic health records, legal frameworks, social media, and big data. ${ }^{15}$ Among these activities, this study focused on the m-health section, which assessed health system level and policy readiness for different $m$-health activities. The survey was based on selfreporting by national subject experts from each country, and 125 countries responded to the survey with 64\% response rate. ${ }^{14}$ The survey was completed between April and August 2015 and reflected the most up-to-date information at the national level. ${ }^{14}$ Secondary data sources for the independent variables included the World Bank, WHO, and International Telecommunications Union (ITU).

\section{STUDY POPULATION}

For the comparative analysis of m-health policy readiness between sub-Saharan Africa and OECD countries, 30 subSaharan African countries and 31 OECD countries were included among the 125 countries that completed the survey. Thus, the study population represents $63 \%$ of sub-Saharan African countries (30 out of 48 countries) and 89\% of OECD member states ( 31 out of 35 member states).

For the analysis on enabling factors associated with m-health policy readiness, data from 112 WHO member states (out of the 125 countries that completed the survey) that provided sufficient details for analysis were included. The remaining 13 countries were excluded because the data for independent variables were mostly unavailable. The 112 countries included 38 high-income countries, 30 upper middle-income countries, 29 lower middle-income countries, and 15 low-income countries. The study population for each set of analysis is summarized in Figure 1.

\section{M-HEALTH POLICY READINESS: THE SCORING SYSTEM}

M-health policy readiness is the primary outcome variable for the two statistical analyses conducted in our study. The variable was scored using the following scheme: for each of the $14 \mathrm{~m}$-health activities such as mobile telehealth and mobile disease surveillance, the respondents from each country could identify their program type as informal, pilot, or established. The score for each m-health activity was assigned as 0 , 1,2 , and 3, reflecting responses of "unanswered," "informal," "pilot," and "established," respectively. Then the total m-health readiness score was calculated by summing up the scores given for each of the $14 \mathrm{~m}$-health activities. The score thus ranges from 0 to 42 for each country. For the unanswered items, no score is added (i.e., the score of 0 ) with the assumption that the specific m-health activity for the unanswered item is either not adopted at the national level or its status is unknown. This is 


\section{LEE ET AL.}

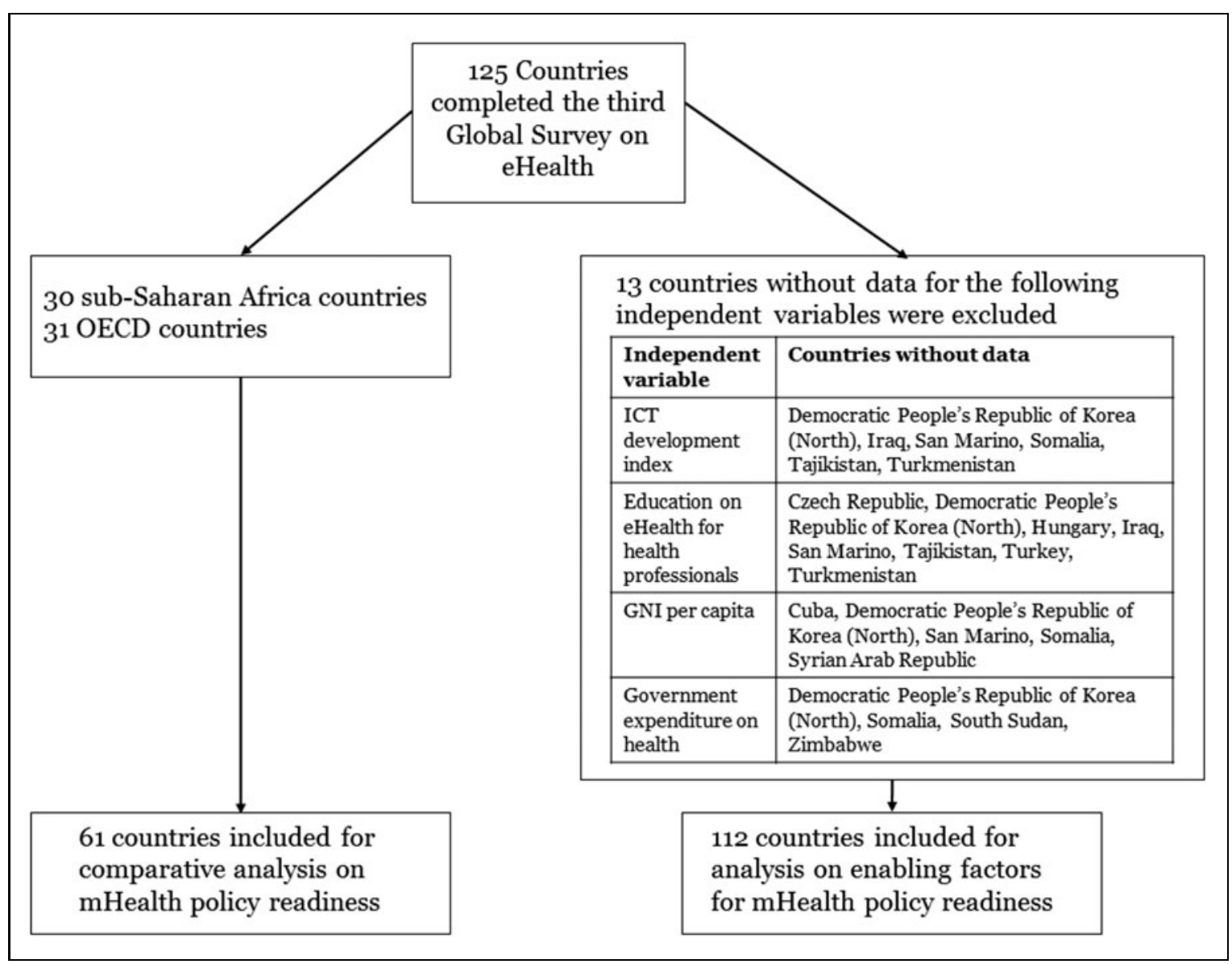

Fig. 1. Study population and analysis plan. GNI, gross national income; ICT, information and communication technology; OECD, Organization for Economic Cooperation and Development.

because the respondents were given possible answer options only for the programs adopted (informal, pilot, and established), and therefore, they had no choice, but to leave the item unanswered for a program that is not implemented. The more detailed scoring method for the $m$-health policy readiness is presented in Table 1 .

\section{STATISTICAL ANALYSIS 1: COMPARISON OF M-HEALTH POLICY READINESS}

For the comparative analysis on $\mathrm{m}$-health policy readiness between sub-Saharan Africa and OECD countries, an independent two-sample $t$ test was conducted. Specifically, the mean difference in $\mathrm{m}$-health policy readiness score was compared between sub-Saharan Africa and OECD countries.

\section{STATISTICAL ANALYSIS 2: EXAMINATION \\ OF ENABLING FACTORS ASSOCIATED \\ WITH M-HEALTH POLICY READINESS}

To identify enabling factors associated with m-health policy readiness, ordinal logistic regression analysis was performed. ${ }^{16}$
The three ordinal outcome categories based on the score for m-health policy readiness were labeled as follows: (1) late adopters, (2) the majority, and (3) innovators. The cutoff values for each ordinal category were determined based on tertiles that divide the range of probability distribution for m-health policy readiness scores into three equal-sized groups. The labels were named based on a modified version of Rogers' diffusion of innovations theory. ${ }^{17}$ The modified version of the theory was developed by Nykiforuk et al. ${ }^{18}$ to assess readiness for policy change in the public health context. Late adopters are those with the lowest scores, indicating informal policy readiness level. Those in the middle are at the pilot stage of policy readiness. The innovators are those who have the highest scores with established formal m-health policy readiness.

The predictor variables were selected based on empirical evidence from the literature. ${ }^{5-10,19}$ First, a country's ICT Development Index (IDI) developed by ITU, which comprehensively measures the level of three components of ICT development, (1) ICT infrastructure and access, (2) ICT use, and (3) ICT skill at 
Table 1. Fourteen m-Health Items from 2015 World Health Organization Third Global Survey on e-Health and Their Scoring

PROGRAM TYPE DEFINITION AND SCORING

\begin{tabular}{r|l|}
\hline \multicolumn{2}{|l|}{ Accessing/providing health services } \\
\hline 1 & Toll-free emergency \\
\hline 2 & Health call centers \\
\hline 3 & Appointment reminders \\
\hline 4 & Mobile telehealth \\
\hline 5 & Management of disasters and emergencies \\
\hline 6 & Treatment adherence \\
\hline Accessing/providing health information \\
\hline 7 & Community mobilization \\
\hline 8 & Access to information, databases and tools \\
\hline 9 & Patient records \\
\hline 10 & M-learning \\
\hline 11 & Decision support systems \\
\hline Collecting health information \\
\hline 12 & Patient monitoring \\
\hline 13 & Health surveys \\
\hline 14 & Disease surveillance \\
\hline
\end{tabular}

ICT, information and communication technology. 0. Unanswered.

1. Informal-Early adoption of mobile ICT for health purposes in the absence of formal processes and policies.

2. Pilot-Testing and evaluating the use of $m$-health in a given situation.

3. Established-An ongoing program using $m$-health that has been conducted for a minimum of 2 years and is planned to continue and has funding support for at least 2 more years.

as a covariate to control for the effect of size of a country's economy on mhealth policy readiness.

One of the important assumptions

for the ordinal logistic regression model is the proportional odds assumption, also known as parallel regression assumption. This assumes that there is only a single set of coefficients in the equation and the effect of each predictor variable on the log odds is the same across the categories of the ordinal outcome variable. ${ }^{16}$ This means that for each predictor variable, the estimated logits or the odds ratios of being at or beyond (or being at or below) categories 1, 2, or 3 are assumed to be the same at each category level. ${ }^{16}$ To test if the proportional odds assumption holds in our model, the Brant test was performed. ${ }^{16}$ All statistical analysis was performed using STATA V14. ${ }^{21}$

\section{Results}

\section{SCORES OF M-HEALTH POLICY READINESS ACROSS SURVEY COUNTRIES}

the national level, was considered. ${ }^{20}$ Different weights were applied for each of these three components. The IDI includes 11 subindices, including mobile phone subscriptions per 100 people and mean years of schooling. ${ }^{20}$ Appendix Table 1 shows the detailed indices under the three components. The IDI is a powerful indicator of a country's capacity for a multifaceted ICT system with a standardized range from 1 to 10. The higher the IDI, the more advanced a country is in terms of ICT capacity.

Second, the e-health education or training for health professionals offered by any institution or association in a country was taken into account. The dichotomous measure on whether e-health education was offered or not was derived from the Third Global Survey on e-Health. Third, the government expenditure on health as percent of total government expenditure was included in the model as financing is a critical component in $m$-health policy readiness. Also, a dummy variable for subSaharan African country versus others was included as the mhealth is growing most rapidly in sub-Saharan Africa, but at the same time, resources are more limited in this region. ${ }^{12}$ Last, a country's gross national income (GNI) per capita was included
Overall, the mean m-health policy readiness score for 112 countries was 19.7 (range 0-42, standard deviation [SD] 12.0). There were 39 countries in the first and second tertiles (late adopters and the majority) and 34 countries belonged to third tertile (the innovators). Among 34 innovator countries, 44\% (15 countries) were high-income countries, whereas $46 \%$ of the late adopters (18 out of 39) were low-income countries or LMICs according to 2015 World Bank income group classification. ${ }^{22}$ Table 2 summarizes the m-health policy readiness groups by income classification.

The mean IDI was statistically different between the innovators (mean 5.60, SD 2.21) and the late adopters (mean 4.49, SD 2.20) $(p=0.03)$. Mean GNI per capita for the innovators was $\$ 23,758$ (SD 18,019) versus $\$ 19,288$ (SD 25,079) for the late adopters. Mean percentage of government expenditure on health for the innovators was $12.8 \%$, whereas for the late adopters, it was $11.7 \%$. There was only a small mean difference in the government expenditure on health between the innovators (12.8\%) and the majority (12.1\%). E-health education or training for health professionals was offered in $94 \%$ of the innovator countries (32 out of 34), while $67 \%$ of the 


\section{LEE ET AL.}

\begin{tabular}{|c|c|c|c|c|}
\hline $\begin{array}{l}\text { WORLD BANK INCOME } \\
\text { CLASSIFICATION (2015) }\end{array}$ & $\begin{array}{c}\text { INNOVATORS, } \\
N(\%)\end{array}$ & $\begin{array}{c}\text { THE MAJORITY, } \\
N(\%)\end{array}$ & $\begin{array}{c}\text { LATE ADOPTERS, } \\
N(\%)\end{array}$ & TOTAL $N(\%)$ \\
\hline High & $15(44)$ & $12(31)$ & $11(28)$ & $38(34)$ \\
\hline Upper middle & $11(32)$ & $9(23)$ & $10(26)$ & $30(27)$ \\
\hline Lower middle & $4(12)$ & $12(31)$ & $13(33)$ & $29(26)$ \\
\hline Low & $4(12)$ & $6(15)$ & $5(13)$ & $15(13)$ \\
\hline Grand total & 34 & 39 & 39 & 112 \\
\hline
\end{tabular}

bilities of m-health policy readiness levels by IDI values. The late adopter groups tended to have higher probability of having low IDI values, whereas the innovators were more likely to have high IDI values.

For the countries that offer e-health education for health professionals, the odds of being above a particular category of $\mathrm{m}$ health policy readiness (higher level of readiness) compared to below that particular category were 4.43 times as large as those for the countries without e-health education for

countries in the late adopter group (26 out of 39) offer such programs. A complete list of $m$-health policy readiness and related country characteristics is available from Appendix Tables 2 to 4 .

\section{LEVEL OF M-HEALTH POLICY READINESS: COMPARISON BETWEEN SUB-SAHARAN AFRICA AND OECD}

Figure 2 illustrates the comparison of m-health policy readiness scores between 30 sub-Saharan African and 31 OECD countries. Five countries with the highest m-health policy readiness scores were all OECD countries (Sweden, Canada, Latvia, Turkey, and United Kingdom). Four out of the five countries ranked with the lowest scores are located in subSaharan Africa (Equatorial Guinea, Guinea-Bissau, Lesotho, and Somalia). The mean score of m-health policy readiness for sub-Saharan African countries was 16.8 (SD 12.0) and that for OECD countries was 23.7 (SD 11.1). There was a statistically significant difference in mean scores of m-health policy readiness for sub-Saharan Africa and the OECD countries with $p=0.02$. The effect size, Cohen's $d$, was 0.6.

\section{ENABLING FACTORS ASSOCIATED WITH M-HEALTH POLICY READINESS}

Descriptive statistics and the associated factors for m-health policy readiness among 112 countries from ordinal logistic regression model are presented in Table 3. The Brant test result indicated that the proportional odds assumption has not been violated ( $p=0.98$ ) and therefore, the proportional odds model for ordinal response could be fitted. The ordinal logistic regression analysis showed that three variables, (1) IDI, (2) ehealth training, and (3) location in sub-Saharan Africa, were statistically significantly associated with the outcome variable, $\mathrm{m}$-health policy readiness. For IDI, the odds of being above a particular category of m-health policy readiness (higher level of readiness) were compared to below that particular category increase by 1.57 for a one-unit increase in IDI, holding all the other predictors constant. Figure 3 presents predicted proba- healthcare professionals. In addition, the odds of being above a particular category of m-health policy readiness for countries located in sub-Saharan Africa were 3.47 times as large as those located elsewhere.

\section{Discussion}

The study measured m-health policy readiness at the country level, comparing the levels between the sub-Saharan African region and high-income OECD countries, and examined enabling factors associated with m-health policy readiness. The mean m-health policy readiness score was found to be significantly lower for sub-Saharan Africa than OECD. It implies that, in general, high-income countries are relatively more prepared for the m-health as a policy option when compared to subSaharan Africa. The result from this study is in line with previous discussions in the literature regarding limited policy support for m-health or e-health in LMICs. ${ }^{10}$ In fact, among 48 sub-Saharan Africa countries, only one country is classified as a high-income country (Seychelles) and the remaining 47 countries are LMICs. ${ }^{22}$ Even though the potential of m-health in LMICs has been widely acknowledged, long-term policy support and buy-in from the leadership in these countries are still more limited than that in high-income countries. ${ }^{5}$ Lower level of policy support for m-health in sub-Saharan Africa can result in ad hoc approach that makes it difficult to establish sustainable environment for m-health.

In this light, challenges that LMICs face have been twofold. First, more evidence is needed on the effectiveness of m-health to gain support for system-level and policy investment. ${ }^{23} \mathrm{An}$ other issue is that establishing a body of evidence requires transformation of current practice of pilots into national or scalable programs, which in turn can be achieved by policy support. ${ }^{24}$ In other words, the key to taking advantage of mhealth in LMICs, including sub-Saharan African region, is the uptake of m-health on a country's health policy agenda. ${ }^{5}$

This study identified that IDI, e-health education for health professionals, and location in sub-Saharan Africa are related 


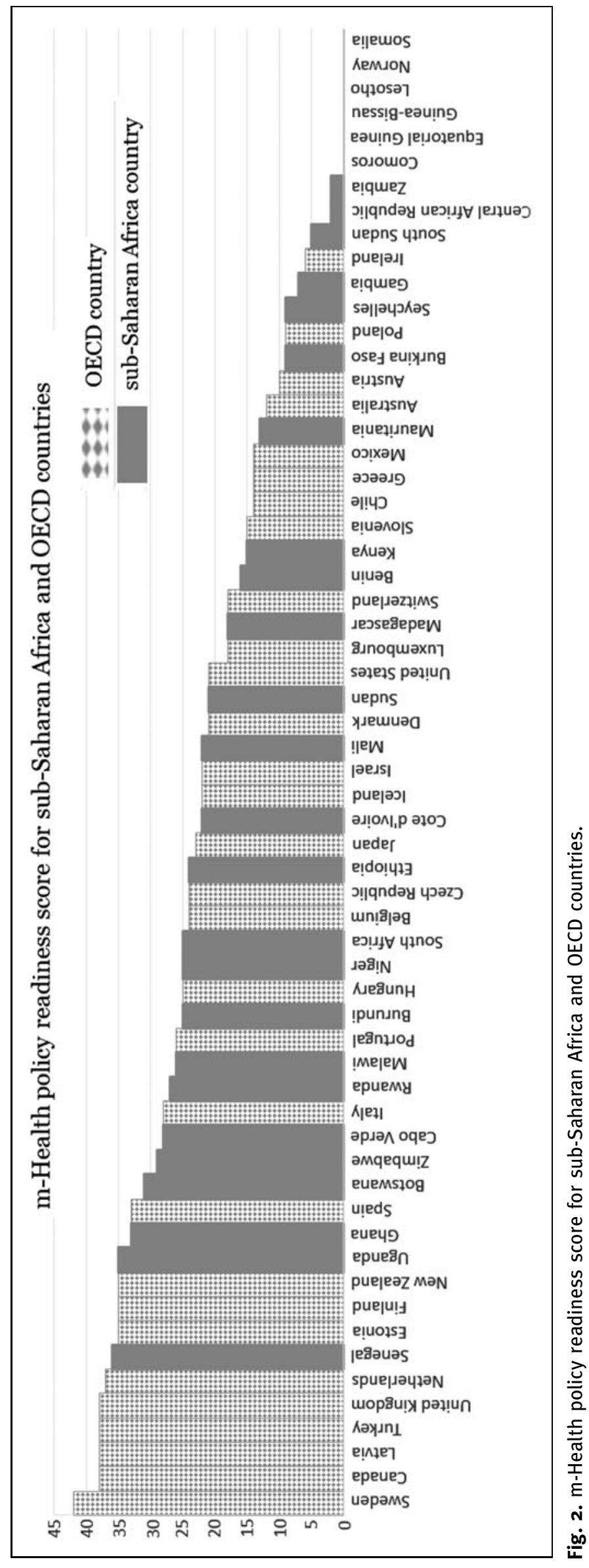




\section{LEE ET AL.}

\begin{tabular}{|c|c|c|c|c|c|c|}
\hline VARIABLES & LATE ADOPTERS & THE MAJORITY & INNOVATORS & COEFFICIENT (SE) & ADJUSTED OR (95\% Cl) & $P$ \\
\hline IDI, mean $(S D)^{a}$ & $4.49(2.20)$ & $4.86(2.35)$ & $5.60(2.22)$ & $0.45(0.17)$ & $1.57(1.12-2.2)^{*}$ & 0.01 \\
\hline GNI per capita, mean $(S D)^{b}$ & $19,288(25,078.6)$ & $19,041(19607.6)$ & $23,758(18018.8)$ & $-0.000025(0.000015)$ & $1.0(0.99-1.0)$ & 0.10 \\
\hline $\begin{array}{l}\text { Government expenditure on health, } \\
\text { mean }(S D)^{c}\end{array}$ & $11.73(4.53)$ & $12.14(4.79)$ & $12.83(4.93)$ & $-0.04(0.04)$ & $0.96(0.89-1.05)$ & 0.42 \\
\hline \multicolumn{7}{|l|}{ E-health training offered, $n(\%)^{d}$} \\
\hline Yes & $26(28.9)$ & $32(35.6)$ & $32(35.6)$ & $1.49(0.52)$ & $4.43(1.60-12.27)^{*}$ & \multirow[t]{2}{*}{$<0.01$} \\
\hline No & $13(59.1)$ & $7(31.8)$ & $2(9.1)$ & Ref & Ref & \\
\hline \multicolumn{7}{|l|}{ Sub-Saharan Africa, $n(\%)^{\mathrm{e}}$} \\
\hline Yes & $10(37.0)$ & $10(37.0)$ & $7(25.9)$ & $1.24(0.60)$ & $3.47(1.06-11.34)^{* *}$ & \multirow[t]{2}{*}{0.04} \\
\hline No & $29(34.1)$ & $29(34.1)$ & 27 (31.8) & Ref & Ref & \\
\hline \multirow[t]{2}{*}{ Intercept } & & & & cut1, $-2.09(0.86)$ & - & 0.02 \\
\hline & & & & cut2, $-3.73(0.91)$ & & $<0.01$ \\
\hline \multicolumn{7}{|l|}{${ }^{*} p<0.01$} \\
\hline \multicolumn{7}{|l|}{${ }^{* *} p<0.05$} \\
\hline \multicolumn{7}{|l|}{ a2015 ICT Development Index. } \\
\hline \multicolumn{7}{|c|}{ b2015 GNI per capita, PPP (current international \$). } \\
\hline \multicolumn{7}{|c|}{${ }^{\text {c}} 2014$ Government expenditure on health (\% of total government expenditure). } \\
\hline \multicolumn{7}{|c|}{${ }^{d}$ E-health training for health professionals offered by any institution or association. } \\
\hline \multicolumn{7}{|l|}{ 'Eocated in sub-Saharan Africa. } \\
\hline
\end{tabular}

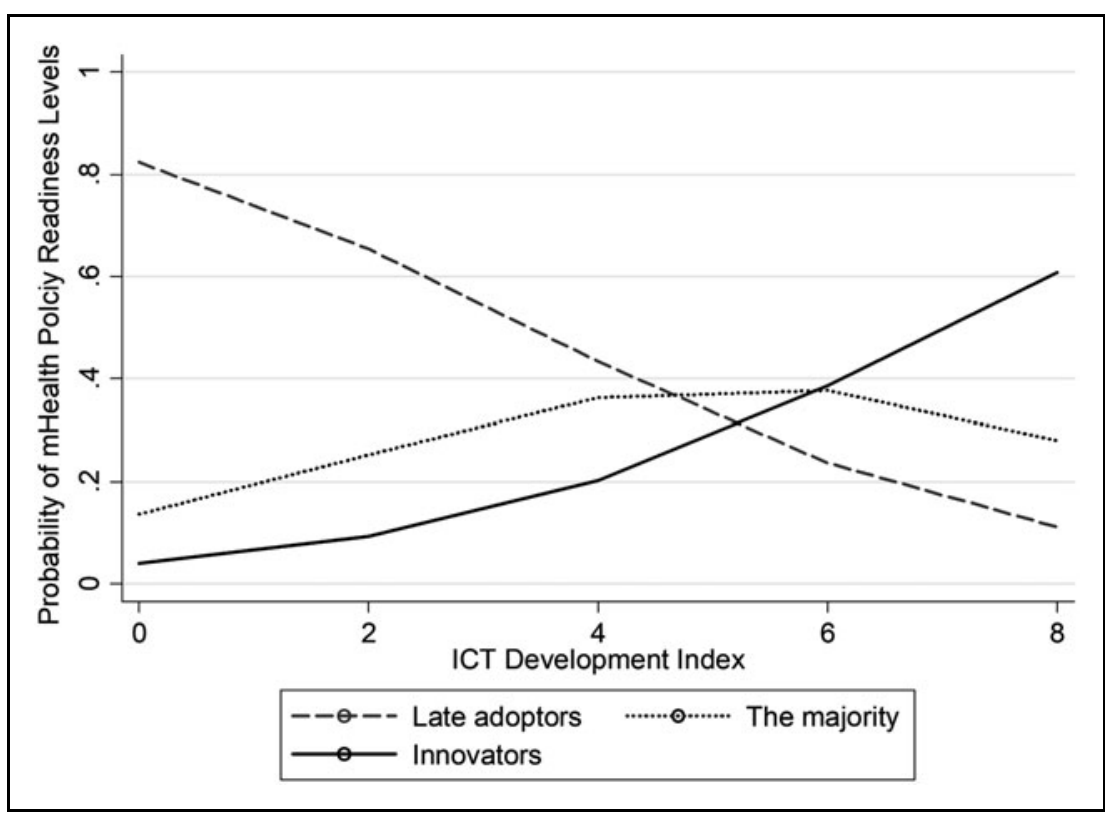

Fig. 3. Predicted probabilities of m-Health policy readiness levels by ICT Development Index. to higher level of m-health policy readiness. These findings are consistent with previous research on m-health adoption and readiness, and provide insights into the way forward for accelerating m-health policy implementation. First, technological readiness and ICT infrastructure are a prerequisite for m-health implementation. $^{8,25,26}$ As the IDI value is a composite measure for ICT access, use, and skills, the technological readiness for $\mathrm{m}$-health not only embraces mobile network coverage or mobile phone subscriptions but also the technology and health literacy of the population. Second, education or training among health professionals should be supported to facilitate m-health adoption. Numerous studies mentioned the importance of education to enhance motivation, technical expertise, and knowledge for m-health among health professionals. ${ }^{7,8,10,19}$ By providing education and training, countries can minimize 


\section{M-HEALTH POLICY READINESS}

reluctance or resistance to the adoption of new technology from health professionals and encourage them to become champions in their organizations. Third, compared to other regions, sub-Saharan Africa has been known to be the place with burgeoning supply and demand for m-health. ${ }^{12}$ The growth of m-health in sub-Saharan Africa over the past decade proved that several countries in this region such as Kenya and South Africa are ready to lead the m-health initiative globally. ${ }^{9}$

Sub-Saharan Africa has dual responsibilities and policy goals in relationship to m-health. On the one hand, it needs to take pilot-based $m$-health to the next policy level by leveraging enthusiasm, availability, and technological capacity. As discussed in this research, technological and educational support are critical for improving overall levels of m-health adoption. In doing so, sub-Saharan Africa can have adequate policy support for m-health at the national and regional level. On the other hand, sub-Saharan Africa can take the lead role for promoting $m$-health practice in the international community. Recently, sub-Saharan Africa has experienced exponential growth in m-health programs with greater availability of mobile technology. The case of sub-Saharan Africa can present examples and best practices that can be applied to other resource-limited settings. Furthermore, a global collaboration for building m-health capacity among LMICs can be led by sub-Saharan African countries with sufficient experience in $m$-health implementation. Lessons learned from the past $m$-health programs in sub-Saharan Africa can be invaluable for other countries that aim to launch $\mathrm{m}$-health programs at the national level.

In conclusion, our study suggests that the m-health policy readiness level for sub-Saharan Africa is lower compared to high-income countries from OECD. This is partly because the majority of m-health programs in sub-Saharan Africa are pilot projects and funded by international development organizations or donors, while OECD countries tend to adopt a systematic approach to m-health as part of national e-health initiative. However, when compared at the global scale, subSaharan Africa is more likely to be at the advanced level in terms of m-health policy readiness. Part of the reason for this is because the recent growth of m-health programs in subSaharan Africa has been outstanding. As the findings of this study indicated, technological and educational support should be considered to improve m-health policy readiness at the national level.

\section{Acknowledgments}

The authors acknowledge the contribution to this work of the World Health Organization, World Bank, and Interna- tional Telecommunications Union for their publicly available information and data. No specific funding was received for this study.

\section{Disclosure Statement}

No competing financial interests exist.

\section{REFERENCES}

1. Donabedian A. Evaluating the quality of medical care. 1966. Milbank Q 2005; 83:691-729.

2. Betjeman TJ, Soghoian SE, Foran MP. mHealth in Sub-Saharan Africa. Int J Telemed App/ 2013;2013:482324.

3. LeFevre $A E$, Shillcutt $S D$, Broomhead $S$, et al. Defining a staged-based process for economic and financial evaluations of mHealth programs. Cost Eff Resour Alloc 2017;15:5.

4. Premji S. Mobile health in maternal and newborn care: Fuzzy logic. Int J Environ Res Public Health 2014;11:6494-6503.

5. Chib A, van Velthoven MH, Car J. mHealth adoption in low-resource environments: A review of the use of mobile healthcare in developing countries. J Health Commun 2015;20:4-34.

6. WHO (World Health Organization). mHealth: New horizons for health through mobile technologies: Based on the findings of the Second Global Survey on eHealth. Geneva, Switzerland: WHO, 2011.

7. Ross J, Stevenson F, Lau R, Murray E. Factors that influence the implementation of e-health: A systematic review of systematic reviews (an update). Implement Sci 2016;11:146.

8. Khatun F, Heywood AE, Ray PK, et al. Determinants of readiness to adopt mHealth in a rural community of Bangladesh. Int $J$ Med Inform 2015;84: 847-856.

9. Folaranmi T. mHealth in Africa: Challenges and opportunities. Perspect Public Health 2014;134:14-15.

10. Mandirola Brieux HF, Bhuiyan Masud JH, Kumar Meher S, et al. Challenges and hurdles of eHealth implementation in developing countries. Stud Health Technol Inform 2015;216:434-437.

11. Labrique $A B$, Vasudevan $L$, Kochi $E$, et al. mHealth innovations as health system strengthening tools: 12 common applications and a visual framework. Glob Health Sci Pract 2013;1:160-171.

12. Gorski I, Bram JT, Sutermaster $S$, et al. Value propositions of mHealth projects. J Med Eng Technol 2016;40:400-421.

13. Bloomfield GS, Vedanthan R, Vasudevan $L$, et al. Mobile health for noncommunicable diseases in Sub-Saharan Africa: A systematic review of the literature and strategic framework for research. Global Health 2014;10:49.

14. WHO. Atlas of eHealth country profiles. Geneva, Switzerland: WHO, 2016.

15. WHO. Third Global Survey on eHealth. In: Global Observatory for eHealth, ed. The use of eHealth in support of universal health coverage. Geneva, Switzerland: WHO, 2015;9-11.

16. Liu X. Applied Ordinal Logistic Regression Using Stata: From single-level to multilevel modeling. SAGE Publications, Thousand Oaks, CA 2015.

17. Rogers EM. Diffusions of innovations theory, 5th ed. New York: Free Press, 2003.

18. Nykiforuk CIK, Atkey KM, Nieuwendyk LM, Raine KD, Reed S, Kyle K. Policy readiness tool: Understanding readiness for policy change and strategies for taking action. Edmonton, AB: School of Public Health, University of Alberta, 2014.

19. Hage $E$, Roo JP, van Offenbeek MAG, Boonstra A. Implementation factors and their effect on e-Health service adoption in rural communities: A systematic literature review. BMC Health Serv Res 2013;13:19-19. 


\section{LEE ET AL.}

20. ITU. The ICT Development Index (IDI): Conceptual framework and methodology 2017. Available at www.itu.int/en/ITU-D/Statistics/Pages/publications/ mis2016/methodology.aspx (last accessed November 26, 2017).

21. StataCorp. Stata Statistical Software: Release 14. College Station, TX: StataCorp LP, 2015.

22. World Bank. World Bank Country and Lending Groups. Available at https://datahelpdesk.worldbank.org/knowledgebase/articles/906519world-bank-country-and-lending-groups (last accessed November 26, 2017).

23. Hurt $K$, Walker RJ, Campbell JA, Egede LE. mHealth interventions in low and middle-income countries: A systematic review. Glob J Health Sci 2016;8: 54429.

24. Kallander K, Tibenderana JK, Akpogheneta OJ, et al. Mobile health (mHealth) approaches and lessons for increased performance and retention of community health workers in low- and middle-income countries: A review. $J$ Med Internet Res 2013;15:e17.

25. Alghamdi M, Gashgari $H$, Househ $M$. A systematic review of mobile health technology use in developing countries. Stud Health Technol Inform 2015; 213:223-226.

26. Aranda-Jan CB, Mohutsiwa-Dibe N, Loukanova S. Systematic review on what works, what does not work and why of implementation of mobile health (mHealth) projects in Africa. BMC Public Health 2014; $14: 188$.

Address correspondence to:

Sun-Young Kim, PhD

Department of Public Health

Graduate School of Public Health Science

Seoul National University

1 Gwanak-ro, Gwanak-gu

Seoul 08826

South Korea

E-mail: sykim22@snu.ac.kr

Received: October 17, 2017

Revised: December 1, 2017

Accepted: December 4, 2017

Online Publication Date: February 12, 2018

\section{Appendix}

\section{Appendix Table 1. ICT Development Index Conceptual Framework and Methodology \\ REFERENCE \\ VALUE WEIGHTS (\%)}

ICT access

\begin{tabular}{c|l|c|c}
\hline 1 & Fixed telephone subscriptions per 100 inhabitants & 60 & 20 \\
\hline 2 & Mobile-cellular telephone subscriptions per 100 inhabitants & 120 & 20 \\
\hline 3 & International Internet bandwidth (bit/s) per Internet user & $976,696^{*}$ & 20 \\
\hline 4 & Percentage of households with a computer & 100 & 20 \\
\hline 5 & Percentage of households with Internet access & 100 & 20 \\
\hline
\end{tabular}

ICT use

\begin{tabular}{c|l|c|c}
\hline 6 & Percentage of individuals using the Internet & 100 & 33 \\
\hline 7 & Fixed-broadband subscriptions per 100 inhabitants & 60 & 33 \\
\hline 8 & Active mobile broadband subscriptions per 100 inhabitants & 100 & 33 \\
\hline
\end{tabular}

ICT skills

\begin{tabular}{r|l|r|r}
\hline 9 & Mean years of schooling & 15 & 33 \\
\hline 10 & Secondary gross enrollment ratio & 100 & 33 \\
\hline 11 & Tertiary gross enrollment ratio & 100 & 33 \\
\hline
\end{tabular}

ICT Development Index. ${ }^{20}$

*This corresponds to a log value of 5.99, which was used in the normalization step.

ICT, information and communication technology. 


\begin{tabular}{|c|c|c|c|c|c|c|c|c|c|}
\hline 1 & Argentina & 35 & 6.21 & 20,010 & 6.92 & Yes & LAC & UM & \\
\hline 2 & Bangladesh & 35 & 2.27 & 3,560 & 5.66 & Yes & SA & LM & \\
\hline 4 & Cabo Verde & 28 & 4.23 & 6,320 & 11.73 & Yes & SSA & LM & \\
\hline 5 & Canada & 38 & 7.55 & 43,900 & 18.77 & Yes & NA & H & OECD \\
\hline 6 & China & 33 & 4.80 & 14,390 & 10.43 & Yes & EAP & UM & \\
\hline 7 & Colombia & 41 & 4.98 & 13,550 & 18.14 & No & LAC & UM & \\
\hline 11 & Finland & 35 & 8.11 & 42,600 & 12.35 & Yes & ECA & H & OECD \\
\hline 12 & Ghana & 33 & 3.75 & 4,080 & 6.82 & Yes & SSA & LM & \\
\hline 13 & Italy & 28 & 6.89 & 37,030 & 13.65 & Yes & ECA & H & OECD \\
\hline 14 & Jordan & 32 & 4.67 & 10,760 & 13.68 & Yes & MENA & UM & \\
\hline 15 & Kazakhstan & 36 & 6.42 & 23,480 & 10.9 & Yes & ECA & UM & \\
\hline 16 & Latvia & 38 & 6.88 & 24,840 & 9.81 & Yes & ECA & H & OECD \\
\hline 17 & Lithuania & 37 & 7.00 & 27,570 & 13.36 & Yes & ECA & H & \\
\hline 18 & Malawi & 26 & 1.49 & 1,140 & 16.77 & Yes & SSA & L & \\
\hline 24 & Pakistan & 42 & 2.15 & 5,320 & 4.73 & Yes & SA & LM & \\
\hline 25 & Paraguay & 36 & 3.88 & 8,680 & 11.92 & Yes & LAC & UM & \\
\hline 26 & Portugal & 26 & 6.64 & 29,060 & 11.91 & Yes & ECA & H & OECD \\
\hline 27 & Russian Federation & 31 & 6.79 & 23,770 & 9.49 & Yes & ECA & UM & \\
\hline 28 & Rwanda & 27 & 1.79 & 1,720 & 9.86 & Yes & SSA & L & \\
\hline 29 & Senegal & 36 & 2.41 & 2,380 & 8.04 & Yes & SSA & L & \\
\hline 30 & Singapore & 38 & 7.88 & 81,360 & 14.15 & Yes & EAP & H & \\
\hline 31 & Spain & 33 & 7.46 & 34,880 & 14.5 & Yes & ECA & $\mathrm{H}$ & OECD \\
\hline 32 & Sweden & 42 & 8.47 & 48,700 & 19.03 & Yes & ECA & $\mathrm{H}$ & OECD \\
\hline 33 & Uganda & 35 & 1.86 & 1,820 & 10.97 & Yes & SSA & L & \\
\hline 34 & United Kingdom & 38 & 8.54 & 40,900 & 16.52 & Yes & ECA & H & OECD \\
\hline
\end{tabular}

${ }^{a} \mathrm{~m}$-Health policy readiness score calculated by scoring method presented in Table 1.

${ }^{\mathrm{b}} \mathrm{IDI}$ value for the year 2015.

'2015 Gross National Income per capita, PPP (current international \$).

dGovernment expenditure on health as percent of total government expenditure for 2014 (latest year available).

${ }^{e} e-H e a l t h$ education or training offered by any institution or association in a country (reported by national subject experts).

${ }^{f}$ Regional classification by World Bank (EAP, East Asia and Pacific; ECA, Europe and Central Asia; LAC, Latin America and the Caribbean; MENA, Middle East and North Africa; NA, North America; SA, South Asia; and SSA, Sub-Saharan Africa).

${ }^{9}$ Income classification by World Bank based on 2015 GNI per capita ( $H$, high income, L, low income; LM, lower middle income; and UM, upper middle income).

GNI, gross national income; IDI, ICT Development Index; OECD, Organization for Economic Cooperation and Development; PPP, purchasing power parity. 


\begin{tabular}{|c|c|c|c|c|c|c|c|c|c|}
\hline NO. & COUNTRY & $\begin{array}{l}\text { M-HEALTH POLICY } \\
\text { READINESS SCORE }\end{array}$ & $|\mathrm{ID}|^{\mathrm{b}}$ & $\begin{array}{l}\text { GNI PER } \\
\text { CAPITA }^{c}\end{array}$ & $\begin{array}{l}\text { GOVERNMENT } \\
\text { EXPENDITURE } \\
\text { ON HEALTH }\end{array}$ & $\begin{array}{l}\text { E-HEALTH } \\
\text { TRAINING } \\
\text { OFFERED }^{\mathrm{e}}\end{array}$ & REGION ${ }^{f}$ & $\begin{array}{c}\text { INCOME } \\
\text { CLASSIFICATION }\end{array}$ & OECD \\
\hline 1 & Algeria & 21 & 3.74 & 14,310 & 9.9 & Yes & MENA & UM & \\
\hline 2 & Armenia & 16 & 5.34 & 8,770 & 7.04 & No & ECA & LM & \\
\hline 3 & Bahrain & 15 & 7.42 & 38,660 & 10.47 & Yes & MENA & $H$ & \\
\hline 4 & Belgium & 24 & 7.69 & 45,660 & 15.1 & Yes & ECA & $\mathrm{H}$ & OECD \\
\hline 5 & Benin & 16 & 1.83 & 2,050 & 9.55 & No & SSA & L & \\
\hline 6 & Bulgaria & 17 & 6.43 & 17,880 & 10.95 & Yes & ECA & UM & \\
\hline 7 & Burundi & 25 & 1.16 & 730 & 13.19 & Yes & SSA & L & \\
\hline 8 & Cambodia & 25 & 2.78 & 3,300 & 6.13 & Yes & EAP & LM & \\
\hline 9 & Cote d'Ivoire & 22 & 2.43 & 3,260 & 7.35 & No & SSA & LM & \\
\hline 10 & Denmark & 21 & 8.77 & 49,240 & 16.77 & Yes & ECA & H & OECD \\
\hline 11 & Ethiopia & 24 & 1.29 & 1,620 & 15.75 & Yes & SSA & L & \\
\hline 12 & Georgia & 21 & 5.33 & 9,340 & 5 & Yes & ECA & UM & \\
\hline 13 & Guatemala & 15 & 3.09 & 7,530 & 17.83 & Yes & LAC & LM & \\
\hline 14 & Iceland & 22 & 8.66 & 47,160 & 15.73 & Yes & ECA & $\mathrm{H}$ & OECD \\
\hline 15 & Iran, Islamic Rep. & 18 & 4.66 & $17,430^{*}$ & 17.53 & Yes & MENA & UM & \\
\hline 16 & Israel & 22 & 7.25 & 36,040 & 11.57 & Yes & MENA & $\mathrm{H}$ & $\mathrm{OECD}$ \\
\hline 17 & Jamaica & 24 & 4.20 & 8,680 & 8.08 & No & LAC & UM & \\
\hline 18 & Japan & 23 & 8.28 & 42,310 & 20.28 & Yes & EAP & $\mathrm{H}$ & $\mathrm{OECD}$ \\
\hline 19 & Kenya & 15 & 2.78 & 3,070 & 12.8 & Yes & SSA & LM & \\
\hline 20 & Lebanon & 16 & 5.91 & 13,750 & 10.72 & Yes & MENA & UM & \\
\hline 21 & Luxembourg & 18 & 8.34 & 72,080 & 13.64 & Yes & ECA & $\mathrm{H}$ & $\mathrm{OECD}$ \\
\hline 22 & Madagascar & 18 & 1.57 & 1,410 & 10.18 & Yes & SSA & L & \\
\hline 23 & Mali & 22 & 2.00 & 1,970 & 5.64 & Yes & SSA & L & \\
\hline 24 & Moldova & 22 & 5.60 & 5,400 & 13.32 & Yes & ECA & LM & \\
\hline 25 & Morocco & 20 & 4.26 & 7,690 & 6.03 & Yes & MENA & LM & \\
\hline 26 & Niger & 25 & 1.03 & 950 & 7.57 & Yes & SSA & $\mathrm{L}$ & \\
\hline 27 & Panama & 16 & 4.63 & 20,460 & 14.63 & Yes & LAC & UM & \\
\hline 28 & Peru & 17 & 4.23 & 12,060 & 15 & Yes & LAC & UM & \\
\hline 29 & Philippines & 25 & 3.97 & 8,940 & 10.01 & Yes & EAP & LM & \\
\hline 30 & Slovenia & 15 & 7.10 & 31,180 & 12.83 & Yes & ECA & $\mathrm{H}$ & OECD \\
\hline 31 & South Africa & 25 & 4.70 & 12,870 & 14.23 & No & SSA & UM & \\
\hline 32 & Sudan & 21 & 2.56 & 3,990 & 11.65 & No & SSA & LM & \\
\hline 33 & Switzerland & 18 & 8.50 & 64,100 & 22.7 & Yes & ECA & $\mathrm{H}$ & OECD \\
\hline 34 & Timor-Leste & 17 & 2.92 & 4,550 & 2.44 & No & EAP & LM & \\
\hline
\end{tabular}




\begin{tabular}{|c|c|c|c|c|c|c|c|c|c|}
\hline NO. & COUNTRY & $\begin{array}{l}\text { M-HEALTH POLICY } \\
\text { READINESS SCORE }^{\mathrm{a}}\end{array}$ & $\left.||^{D}\right|^{b}$ & $\begin{array}{l}\text { GNI PER } \\
\text { CAPITA }^{c}\end{array}$ & $\begin{array}{l}\text { GOVERNMENT } \\
\text { EXPENDITURE } \\
\text { ON HEALTH }^{d}\end{array}$ & $\begin{array}{l}\text { E-HEALTH } \\
\text { TRAINING } \\
\text { OFFERED }^{\mathrm{e}}\end{array}$ & REGION $^{f}$ & $\begin{array}{c}\text { INCOME } \\
\text { CLASSIFICATION }^{g}\end{array}$ & OECD \\
\hline 35 & Trinidad and Tobago & 23 & 5.48 & 32,180 & 8.17 & Yes & LAC & H & \\
\hline 36 & Ukraine & 23 & 5.21 & 7,840 & 10.8 & Yes & ECA & LM & \\
\hline 37 & United States & 21 & 8.06 & 57,540 & 21.29 & Yes & NA & H & OECD \\
\hline 38 & Uruguay & 25 & 6.44 & 20,400 & 20.77 & Yes & LAC & H & \\
\hline 39 & Uzbekistan & 23 & 3.76 & 6,200 & 10.74 & Yes & ECA & LM & \\
\hline
\end{tabular}

*Data from year 2014.

${ }^{a} \mathrm{~m}$-Health policy readiness score calculated by scoring method presented in Table 1.

'IDI value for the year 2015.

c2015 Gross National Income per capita, PPP (current international \$).

${ }^{\mathrm{d}}$ Government expenditure on health as percent of total government expenditure for 2014 (latest year available).

e e-Health education or training offered by any institution or association in a country (reported by national subject experts).

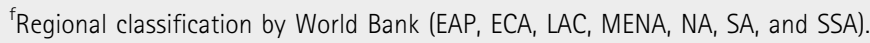

${ }^{g}$ Income classification by World Bank based on 2015 GNI per capita (H, L, LM, and UM). 


\begin{tabular}{|c|c|c|c|c|c|c|c|c|c|}
\hline NO. & COUNTRY & $\begin{array}{l}\text { M-HEALTH POLICY } \\
\text { READINESS SCORE }^{\mathrm{a}}\end{array}$ & $\left.||^{b}\right|^{b}$ & $\begin{array}{l}\text { GNI PER } \\
\text { CAPITA }^{c}\end{array}$ & $\begin{array}{l}\text { GOVERNMENT } \\
\text { EXPENDITURE } \\
\text { ON HEALTH }\end{array}$ & $\begin{array}{l}\text { E-HEALTH } \\
\text { TRAINING } \\
\text { OFFERED }^{\mathrm{e}}\end{array}$ & REGION ${ }^{f}$ & $\begin{array}{c}\text { INCOME } \\
\text { CLASSIFICATION }^{g}\end{array}$ & OECD \\
\hline 1 & Afghanistan & 13 & 1.62 & 1,940 & 12 & Yes & SA & LM & \\
\hline 2 & Albania & 8 & 4.62 & 11,310 & 9.37 & No & ECA & UM & \\
\hline 3 & Australia & 12 & 8.18 & 45,320 & 17.31 & Yes & EAP & $\mathrm{H}$ & OECD \\
\hline 4 & Austria & 10 & 7.53 & 49,160 & 16.27 & Yes & ECA & $\mathrm{H}$ & OECD \\
\hline 5 & Azerbaijan & 8 & 6.23 & 17,170 & 3.88 & No & ECA & UM & \\
\hline 6 & Belarus & 3 & 7.02 & 16,920 & 13.79 & Yes & ECA & UM & \\
\hline 7 & Bhutan & 9 & 3.12 & 7,630 & 8.03 & No & SA & LM & \\
\hline 8 & Bosnia and Herzegovina & 7 & 5.03 & 10,900 & 14.11 & Yes & ECA & UM & \\
\hline 9 & Burkina Faso & 9 & 1.60 & 1,660 & 11.16 & No & SSA & L & \\
\hline 10 & Central African Republic & 2 & 1.00 & 620 & 14.17 & No & SSA & L & \\
\hline 11 & Chile & 14 & 6.11 & 22,760 & 15.88 & Yes & LAC & $\mathrm{H}$ & OECD \\
\hline 12 & Comoros & 0 & 1.70 & 1,490 & 8.66 & No & SSA & L & \\
\hline 13 & Croatia & 12 & 6.83 & 22,380 & 13.99 & Yes & ECA & $\mathrm{H}$ & \\
\hline 14 & Cyprus & 0 & 6.28 & 31,660 & 7.58 & Yes & ECA & $\mathrm{H}$ & \\
\hline 15 & El Salvador & 11 & 3.64 & 8,240 & 16.69 & Yes & LAC & LM & \\
\hline 16 & Equatorial Guinea & 0 & 1.82 & 27,200 & 6.96 & No & SSA & UM & \\
\hline 17 & Gambia & 7 & 2.40 & $1,580^{*}$ & 15.31 & Yes & SSA & $\mathrm{L}$ & \\
\hline 18 & Greece & 14 & 6.86 & 26,530 & 9.98 & Yes & ECA & $\mathrm{H}$ & OECD \\
\hline 19 & Guinea-Bissau & 0 & 1.34 & 1,450 & 7.79 & No & SSA & L & \\
\hline 20 & Honduras & 8 & 3.00 & 4,750 & 15.4 & Yes & LAC & LM & \\
\hline 21 & Ireland & 6 & 7.73 & 54,610 & 13.44 & Yes & ECA & $\mathrm{H}$ & $\mathrm{OECD}$ \\
\hline 22 & Kiribati & 0 & 2.07 & 4,230 & 5.81 & Yes & EAP & LM & \\
\hline 23 & Kyrgyz Republic & 0 & 3.85 & 3,310 & 11.92 & Yes & ECA & LM & \\
\hline 24 & Lao PDR & 5 & 2.21 & 5,400 & 3.44 & No & EAP & LM & \\
\hline 25 & Lesotho & 0 & 2.47 & 3,290 & 13.08 & Yes & SSA & $\mathrm{LM}$ & \\
\hline 26 & Maldives & 0 & 4.68 & 11,480 & 26.59 & Yes & SA & UM & \\
\hline 27 & Mauritania & 13 & 1.90 & $3,710^{*}$ & 6.01 & Yes & SSA & $\mathrm{LM}$ & \\
\hline 28 & Mexico & 14 & 4.45 & 16,860 & 11.58 & Yes & LAC & UM & OECD \\
\hline 29 & Mongolia & 12 & 4.54 & 11,220 & 6.72 & Yes & EAP & $\mathrm{LM}$ & \\
\hline 30 & Montenegro & 7 & 5.76 & 16,460 & 9.84 & Yes & ECA & UM & \\
\hline 31 & Norway & 0 & 8.35 & 65,430 & 18.21 & Yes & ECA & $\mathrm{H}$ & OECD \\
\hline 32 & Poland & 9 & 6.56 & 25,930 & 10.7 & Yes & ECA & $\mathrm{H}$ & OECD \\
\hline 33 & Oatar & 14 & 6.78 & 138,480 & 5.83 & Yes & MENA & $\mathrm{H}$ & \\
\hline 34 & Romania & 0 & 5.92 & 21,610 & 12.84 & No & ECA & UM & \\
\hline
\end{tabular}




\begin{tabular}{|c|c|c|c|c|c|c|c|c|c|}
\hline NO. & COUNTRY & $\begin{array}{l}\text { M-HEALTH POLICY } \\
\text { READINESS SCORE }^{a}\end{array}$ & $\mathrm{IDI}^{\mathrm{b}}$ & $\begin{array}{l}\text { GNI PER } \\
\text { CAPITA }^{c}\end{array}$ & $\begin{array}{l}\text { GOVERNMENT } \\
\text { EXPENDITURE } \\
\text { ON HEALTH }^{d}\end{array}$ & $\begin{array}{l}\text { E-HEALTH } \\
\text { TRAINING } \\
\text { OFFERED }\end{array}$ & REGION ${ }^{f}$ & $\begin{array}{c}\text { INCOME } \\
\text { CLASSIFICATION }^{\mathrm{g}}\end{array}$ & OECD \\
\hline 35 & Serbia & 0 & 6.43 & 13,420 & 13.86 & No & ECA & UM & \\
\hline 36 & Seychelles & 9 & 4.77 & 25,670 & 9.7 & No & SSA & H & \\
\hline 37 & Tunisia & 0 & 4.49 & 11,100 & 14.16 & No & MENA & LM & \\
\hline 38 & Vietnam & 14 & 4.02 & 5,720 & 14.22 & Yes & EAP & LM & \\
\hline 39 & Zambia & 2 & 2.05 & 3,640 & 11.31 & Yes & SSA & LM & \\
\hline
\end{tabular}

*Data from year 2014

${ }^{a} \mathrm{~m}$-Health policy readiness score calculated by scoring method presented in Table 1.

'IDI value for the year 2015.

c2015 Gross National Income per capita, PPP (current international \$).

${ }^{\mathrm{d}}$ Government expenditure on health as percent of total government expenditure for 2014 (latest year available).

e e-Health education or training offered by any institution or association in a country (reported by national subject experts).

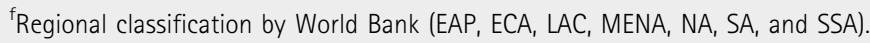

${ }^{g}$ Income classification by World Bank based on 2015 GNI per capita (H, L, LM, and UM). 